\title{
Fin de un ciclo
}

La Sociedad Española de Cirugía Oral y Maxilofacial (SECOM) fue fundada en el año 1965 y este año 2010 celebramos sus 45 años de vida. Ya en sus estatutos originales destacaba como fines primordiales el desarrollo científico de esta especialidad, que hasta el año 1977 no le fue dada la oficialidad. Para ello era fundamental tener un "órgano oficial de expresión" que pudiera servir de conexión entre todos los asociados. Nació entonces la Revista, inicialmente Revista Iberoamericana, que posteriormente en el año 1986 pasó a denominarse Revista Española de Cirugía Oral y Maxilofacial (Rev Esp Cir Oral Maxilofac) (RECOM).

La revista al principio vio la luz con mucho más entusiasmo que medios, ya que entonces los recursos económicos no es que fueran escasos, es que eran inexistentes. Así, lo que cuentan los más viejos del lugar, es que el director de la publicación era el que iba "mendigando" ayudas pecuniarias a los entonces escasos laboratorios y casas comerciales que tenían relación con esta joven y desconocida especialidad.

Su fundador y primer director fue el Dr. Francisco Alarcón Mena y contó con un grupo de veintiséis redactores, todos ellos notables cirujanos orales y maxilofaciales. Se editaron tres números anuales con no pocos esfuerzos de su director para tener un banco de artículos suficiente para editar todos los números. En el año 1986 cambió el director siendo el Dr. Francisco Díaz González, cambiando también el comité de redacción por un Secretario y dos coordinadores científicos. En el año 1988 el entonces Presidente de la SECOM, el Dr. Juan Sebastian López Arranz, firmó el contrato con Jaime Masip en calidad de Administrador de la nueva editorial, ERGON, que editaría 3 números al año y a la que la SECOM le abonaría la cantidad de 810.000 pesetas anuales. La publicidad era enteramente gestionada por la editorial.

En 1993 la junta directiva de la SECOM a propuesta del Dr. Díaz González, eligió al Dr. Juan José Verdaguer Martín como Director de la misma, pasando a ser el secretario general el Dr. José Luis Gil-Diez Usandizaga y creándose comités de redacción y comités científicos, integrados por un grupo de veintisiete especialistas, dando una mayor participación a los mismos en las tareas de evaluación de los trabajos científicos publicados. En 1998 se empezaron a publicar seis números anuales que fueron incluidos en la página web de la sociedad (www.secom.org) así como los libros de resúmenes de ponencias y comunicaciones libres de nuestros congresos y jornadas quirúrgicas en formato de suplemento.

En el año 2000 el Dr. Rafael Martín-Granizo López pasó a desempeñar el cargo de Subdirector, que entonces se denominó Director Adjunto, y se procedió a hacer una importante remodelación de los comités, creándose un Comité Consultivo Internacional, un Comité de Redacción y un Comité Consultivo Nacional formado por 25 miembros revisores, así como una estructuración en $8 \mathrm{sec}$ ciones del contenido de la revista, creándose la página del residente y la revisión bibliográfica de los artículos más interesantes publicados en revistas internacionales. Posteriormente bajo la presidencia de la Sociedad del Dr. Miguel Burgueño García en el año 2005 y tras firmar un acuerdo con la Asociación Latinoamericana de Cirugía y Traumatología Bucomaxilofacial (ALACIBU) (http://www. alacibu.org) y con la Associación Portuguesa de Cirurgia Craniomaxilofacial (APCCMF) (http://www.apccmf. org) por la cual la revista pasaba a ser el órgano científico oficial de estas organizaciones, se adhirieron un grupo de vocales latinoamericanos y portugueses que actúan como revisores, comenzándose a difundir la revista por aquellos países por medio de sus respectivas Sociedades científicas. En el año 2007, y coincidiendo con el 30 aniversario de la fundación de la misma, el Dr. Rafael Martín-Granizo López fue nombrado Director de la revista siendo el nuevo Director Adjunto el Dr. José Ignacio Salmerón Escobar.

Hoy termina una etapa de 21 años de relación con la editorial ERGON. Las razones son varias, aunque ninguna queja hacia ellos. Hasta ahora la revista ha funcionado con gran esfuerzo editorial, a golpe de correo postal, lapicero y goma y mucho cariño, sobre todo por parte de dos excelentes profesionales a las que tanto les tenemos que agradecer, primero Rosi Mosquera y luego Lucía Agudelo. Ellas han hecho el trabajo duro. ¡Gracias a todo el equipo de ERGON!.

Pero los tiempos cambian, la informática se ha metido de lleno en nuestras vidas y la gestión de las publicaciones online, sin papel, es la tendencia actual. Para ello teníamos que dar el salto y agruparnos con una de las "grandes" editoriales mundiales. La elegida fue ELSEVIER, con más de 70 publicaciones indexadas a nivel mundial. Porque éste en realidad es nuestro principal objetivo, indexar nuestra revista en Medline, pues si no es así, la revista "casi" no existe y estaría condenada a desaparecer. En futuros editoriales hablaré de los pros y contras de este modelo de gestión de publicaciones. Aunque nada de esto será posible sin que tú, lector, escribas y envíes tus artículos a publicar a nuestra revista.
Rafael Martín-Granizo López Director 